\title{
Sociological Analysis of the Institutional Status of Contemporary Sport
}

\author{
Kurbatova L.N. \\ Sociology and Political Science Department \\ Perm National Research Polytechnic University, PNRPU, \\ Perm, Russia \\ kurbatova-ln@mail.ru
}

\begin{abstract}
The phenomenon of sport, which is currently determined as a specialized field of the social activity, is associated with the identification and demonstration of people's physical abilities.The sociological analysis of sport nowadays becomes an urgent issue of growing practical and theoretical significance. Sport begins to emerge as a social institute in the system of physical culture of society. Thus, the study of the youths' attitude to sport allows to define the overt and latent processes, that uncover the problem area of current sport. At the present moment the recruitment of migration in sport, gambling, political blackmail in the field of sport are involved extensively. The heroic spirit of sport is becoming a thing of the past, although nostalgia for this social phenomenon still persists. This is especially emerging among young people, who, supposedly, are expected to be most actively integrated into this social institution. The sociological study conducted in 2015 by the Perm National Research Polytechnic University revealed a spectrum of the political and economic contradictions of sports and their social status in contemporary society. Students point out the pronounced tendencies of the commercialization and politicization of sport in Russia, its marketability and commercial value. Although nostalgia for the Soviet model of sport and its social role is remained by them.
\end{abstract}

Keywords-sport; students; political status of sport; commercialization of sport; migrant athletes; illegal gambling

\section{INTRODUCTION}

The modern researches of sports as a social institution are carried out within the framework of the structural and functional analysis. It means, that a standard set of functions is singled out, in which a major and universal function becomes the health protection both of a nation and a person.

More often children, teenagers, young people are becoming the objects and subjects of sports, which is quite natural at first glance, because of their age, psyche, physical activity, sociocultural ambitions. The second major function is the sociocultural function, which focuses on the organization of free time, but again under the slogan "health protection." It would seem that the health of a person, a nation is the basis that determines the orientation in the institutional space of society, the state. This is the focus of the Federal Target Program "Development of Physical Culture and Sports in the Russian Federation for 2016-2020"[1]
However, the institutionalization of sport during the $\mathrm{XX}$ century demonstrates, that the sport as a social institution considers "health" as not only and not quite an object of health protection, but as a "commodity" on the sports market. Such an approach to sport has reasonable grounds, since if a society is built on the model of market relations, then, naturally, all social, socio-physiological objects on the market should be a commodity. Therefore, on the one hand, sport is forced to adapt to this social role, while on the other hand, the commercialization of sport is becoming an integral part of business interests. That's exactly why the commercialization of sport is paid too much attention in the literature on sport ethics. As the experts occupied in the researches in this field of sport notice, that the commercialization generates inequities, undermines sport and morally corrupts those, who involved in it. On the other hand, sport retains its visibility, imagery, and emotionality, so strict procedures for business sport cannot be justified [2].

The coordination of such relations is both challenging and essential for the political system of a state. Exactly in this sphere arises the problematic field of sport, which is permeated by the political ambitions of the main political players using sport as a means of political and economic manipulation [3], [4]. However, today "elite sport" is actively promoted, which, according to some authors, should serve as a "peacemaker", i.e "The philosophy behind the United Kingdom's model of sport - and that of several other advanced states - we term a 'virtuous cycle' of sport, whereby elite sport success is seen to lead to both international prestige for the nation, a 'feel-good factor' among the population and, importantly, to an increase in participation among the masses" [5].

\section{LITERATURE REVIEW}

If for the USA and Europe the market nature of sport was originally laid down, then, for example, for Russia this is a new social phenomenon that is actively getting used to our existence in the post-Soviet period [6]. To institutionalize the sport into the Russian reality it is needed not only to develop and implement sports program, but also the willingness of Russians to accept sports as an object and subject of the sports market. Sport refers to those social phenomena that are both 
the object and subject of human social interests. Having arisen as a result of the transformation of the human body, its physiology in the process of biological evolution of a human the constant improvement of the body to fight for survival in the unpredictable environment of wildlife, sport has become an incentive for further development of the body and soul: "A healthy mind in a healthy body!" [7], [8]. For this reason, it is necessary to proceed from the fact that initially in the human community "sport" was perceived as a means of determining the best physical qualities of Homo sapiens, which allowed a person to differentiate the "socio-physiological functions" necessary for the group to survive. This is the explanation why initially each fellow tribeman was called in accordance with his psychomorphophysical qualities and abilities, for example, "Eagle eye", "Flying arrow", etc. Everyone was compared with images of birds and animals: "Falcon - bright eye", "Swift-footed like an antelope", "Sly like a fox", "Strong like a bear", etc. "Ethnic competitions" still exist and are actively supported in all ethnic groups, which once again emphasizes the primordial nature of "sport" in relation to "physical culture" as an institutionalization of the physical body culture. In the scientific literature, this phenomenon has been called "ethnosport" (Russian version) or "traditional games" (Western European version) [9]. Nevertheless, the concept of "traditional games" does not reflect the ethnic nature of sport, as "tradition" is not always formed under the influence of national (ethnic) trait, its social nature may be wider in the sociocultural realm.

From 776 BC the motto of the Olympic Games is still used "Citius, Altius, Fortius!", what means "Faster, Higher, Stronger!". Each Olympic Games is accompanied by an Olympic mascot, which most often represents an animal that characterizes the "natural culture" of the host country. The spirit of adversarial principle and competition is imbued with all historical eras [10]. Sport has become a powerful factor in encouraging people to achieve their goals both in their daily lives and in society.

The socio-cultural and socio-psychological influence of sport on a person is conditioned by different statuses of sport and its social prestige. Sports competitions induce a storm of emotions, delight, pleasure in some individuals and such people join the ranks of fans. Some sports are commensurated with art. The ballet, for example, has too much in common with rhythmic-sportive gymnastics, figure skating, synchronized swimming, acrobatics, springboard diving and etc. Others (we call them athletes) are attracted by the opportunity to discover or reveal their potential physical abilities; they themselves are actively engaged in sports. For third sport becomes a way to realize themselves in others they are coaches, sports referees, sports doctors.

The forth group comprises people, who treat the sport as income source. Most often they perform the functions of management in the field of sport. They can be divided into legal, semi-legal and illegal organizers of sporting events, as they are engaged in sports manipulation. Among them are: "sports managers," "sports breeders," "sports agents," "sports bookies," "sports dealers."
Thus, sport as a complex of socio-cultural, socio-biological and socio-psychological factors forms a certain type of attitude to sport as one of the social needs of a person. Sport as a social institution influences society and the individual through a social institution such as politics. Therefore, sport, on the one hand, is governed by the politics, on the other hand, manages politics. This symbiosis characterizes the dualism of sport. However, as scientific practice shows, there is scant number of researches dedicated to sport social phenomenon [11]. In this aspect, we can talk about the socio-political status of sport, which has important socio-cultural and socio-political significance for different countries [12].

Everyone knows that in Ancient Greece during the Olympic Games all fighting ended Over time, sport became an arena for the realization of political ambitions, a "peaceful battlefield" [13], [14], [15], [16], [17]. However, there are tragic events in the history of the Olympic Games. Thus, in 1972, during the Olympics in Munich, the targeted victims of the terrorist attack were athletes of Israel. This subsequently led to a response. The tragic events ended football matches between Honduras and El Salvador in 1969. This year began a war between the two countries, which was dubbed "football" [18]. One of the most common forms of resolving political contradictions was the boycott of the Olympic Games. The echoes of events such as 1920 Summer Olympics, 1984 Olympic Games in Moscow, 1984 Olympic Games in Los Angeles have not been silenced. It should also be noted that on the eve of the 2008 Olympic Games in Beijing and Sochi 2014 the information about the alleged boycott of these Games by the United States and its allies was actively probed.

Thus, sport is politics and business, sport is culture and morality, sport is a profession and the production of human material. Consequently, sport is a subject and object of the institutionalization.

\section{RESEARCH METHODOLOGY}

The nature of social processes taking place in sports as a social institution has been investigated through sociological methods. The sociological study "Student Attitudes to Sports" conducted among students of the Perm National Research Polytechnic University in May 2015 (N=202) is based on the author's methodology. It includes the following blocks: student types in relation to sports ("athletes," "physicalists," "fans," "indifferent"); sport as a social value in the lives of students; institutional conditions for shaping the nature of students' attitudes towards sport; the sporting interests of students; the cultural phenomenon of sport; the economic phenomenon of sport or the "sports market"; sports and politics. The block that reveals the factors of influence on students' attitude to sports: material costs for sport; restrictions on sport; the impact of Russian sportive achievements on Russia's credibility; satisfaction with sports information; the attitude of friends, girlfriends to sports; parents' attitude to sports; influence on attitudes towards sport; the impact of sports on life's success. Personal block: gender, type of settlement before admission to university, social situation of parents, level of education of parents, financial situation of the student. 
The methodology contains 204 social indicators. This study highlights two social aspects of sport: the politicization and commercialization of sport.

\section{RESULTS}

\section{Politicization of sport}

The most students responded that the sport has a political status, i.e. it is included into political interrelations. Therefore, $82.4 \%$ of students pointed out that sport in Russia increases prestige of the country on the international level. At the same time, there are students who do not want to equate sport and politics. One in six students $(16 \%)$ considers, that "Sport is sport, politics is politics, they are not connected to each other" and "Sport and politics should not be linked together, sport should be developed as the basis of people's physical health, and politics should be strengthened by political means." As we can see, a certain part of young people considers "health preservation" as the major function of sport. Consequently, for some Russians, sport continues to be associated with physical health, not politics. At the same time, a quarter of students (26\%) noted: "Sport contributes to the political stand-off between states." Thus, the political status of sport is perceived by the students ambiguously: on the one hand, they accept the political role of sport as a regulator of international relations, on the other - would like to see sport outside of politics.

It is this approach that predetermined the attitude of students to the Olympic Games or world championships in Russia. The opinion, that Russia has a positive influence on global community in this matter, was expressed by $40 \%$ of students. Students believe that these events "expand the international relations between people of different countries" (29\%), "increase patriotism" (27\%), "stimulate the development of sport in Russia" (25\%), and "Develop the economic and social living conditions of people" (23\%), one in four (24\%) - "It's a waste of huge money that could be used for the significant needs of the country" and $26 \%$ of students "This is a way of corruption and illegally enriching of those, who participate in these activities." And this opinion is held by both boys and girls.

Consequently, the political status of sport is ambiguously perceived in the mass youth consciousness, what points at the serious problems regarding the political situation in the country. In this case, "sport" is a litmus test that manifests the political degree of social tension in society.

\section{Commercialization of sport}

The expansion of sport market has led to the commercialization of sports, the legalization of many previously illegal sports, the development of commercial competitions, such as "The Diamond League", "The Golden League", "The Grand Prix", etc. in athletics. In other sports the commercialization is also actively developing, although the competitions are often informal, unlike athletics, tennis, football, martial arts, sports tourism, etc.

The commercialization of sport induced the emergence and prospering of such a phenomenon as "illegal gambling" "illegal bets," "match-fixing," "sports fraud." All this has an illegal structure of sports management. According to the President of the International Olympic Committee (IOC) Jacques Roge "Match-fixing has not yet been discovered at the Olympic Games, but we are not naive. We know that this day will eventually come. Illegal betting is a cancerous tumor on the body of sport that is growing and penetrates many parts of the world and which is not controlled in any way " [19]. The International Centre for Sports Safety (ICSS) and researchers at the University of the Sorbonne (France) has published a joint report entitled "Protecting the Integrity of Sport Competition - The Last Bet for Modern Sport", which indicates on the growing threat posed by gambles and betting offices [20]. The problem is exacerbated by the Internet: "Part of the illegal betting market has migrated to the Internet, where it provides participants with anonymity, liquidity and ample opportunities for betting. Athletes, coaches, officials and others associated with sports are becoming more and more tempted, and they are under increasing pressure from bettors who want to adjust the results of sports in their favor." $[19,20]$.

The survey of students showed that they, too, did not escape such a fate as the desire to bet. One in five do not mind to make a bet, but only in a legal bookmaker, at the same time the same number of students are ready to bet with illegal bookmakers. One in ten students has already "felt the win" and is therefore ready to bet regardless of their status. Among a certain part of students, the gambles are made within the group, as the students note, it is "so interesting and reliable".

"Trading" in athletes, coaching staff is one of the national tragedies of the modern state. However, $67 \%$ of students perceive this phenomenon as a natural event of contemporary society. Therefore, many students (from 40 to $50 \%$ ) consider in this aspect the essence of illegal sports, such as "dogfights" and "fights without rules". One in five students believes that an individual has a right to "sell" him/herself in the "labour market" and sport is a "labour market".

\section{Migrationalization in sport}

The connection of sociopolitical and socioeconomic status in sport has created the unique social phenomenon for the XX century which is called the "sport migration".

The globalization of sport, its popularization at the international level and commercialization have enlarged the migration space of sports. If the United States as the state was formed from migrants, and as consequence, its sport potential is determined by the natural qualities and capabilities of certain ethnic groups migrating to America within the whole historical time of its existence, while in other countries the sport basic was created by the title population. We can say that the sport interests of the USA on the World's sports arenas are represented by a team consisting of international migration or, in other words, it is the Global, international team. The United States to maintain its sporting superiority, and other countries to compete with the United States in sports, it is necessary to have the appropriate material means and human potential. Any sport team constantly needs "fresh sport powers". Of course, it is possible to grow the younger generation, however, it takes a lot of time for them to become a worthy representative of their state at the World level, but the time is a weak link in sports. 
In order to support the high sport status of the country, the "sport labour migrants" are needed [21,22].

The XX century is rightly considered the century of big sports. However, the big sport makes the big money. Consequently, in order to be on the top of big sport, it is needed not only to invest finances, but to have a very good, in many cases the "great human material". For this purpose, it is required to create a global, international market.

Nowadays, the "trading" in athletes and trainers on the international sport market is being maintained very actively. Based on data of the American researchers, over the past ten years the number of migrant sportsmen has increased in 3 times [21]. At the International Athletics Competitions, for example, it is not easy to determine by appearance what country is represented by a sportsman. The English commentators even use towards their migrant sportsmen the term "paper citizens".

Such a situation is observed in France and in other European countries. Though the priority in this process is still being belonged to the United States and Canada.

After the USSR collapse in the Middle-Asian countries the sports are represented by sportsmen with Russian last names. Russia has not been spared by this fact. Although it not yet possible to talk about a full-scale migration sport movement.

For example, at the 2014 Olympic Games in Sochi, the champions came from Korea - Victor An, the United States Vik Wild, Ukraine - Tatyana Volosozhar. The migrant athletes are in demand in athletics and in team sports: football, basketball and hockey. However, over recent years the situation in athletics has been changed. Many athletes have returned from the United States to their motherland (Kenya, Ethiopia, Jamaica and others). Paradoxically, it is the activity of American sport migration has led to the development of sport in Africa, Asia, South America and other parts of the globe. Today, athletes from African countries compete on an equal footing with athletes from the United States. In migrational sport China is the most national sustainable.

The attitude of students to the "migration sport model" is mostly negative. For example, every second student noticed: "I don't think that the earned medals by migrant sportsmen are supposed as the success for the Russian sport. It is not sport, but the market of medals, like who pays more is a winner". More than $20 \%$ of students consider the migrant sportsmen win the medals for the country is good, but at the same moment "there is a feeling of dissatisfaction with the fact that we have not been able to prepare our own Russian sportsmen of such level." One in five of the respondents reacted more harshly to this situation: "if they are paid, they are obliged to win medals for the country." At the same time, every tenth person does not care who will bring medals to the country, the main thing is a victory.

\section{CONCLUSION}

Politicization and commercialization of sport by leaps and bounds "go on the planet" involving Russia in this process. Today, the ideology of sports has changed, and students view sport through the prism of economic relations: «Nowadays, money decides everything in sport, and we live in a world where the money is the highest value." However, there are still illusions in contrast to this point of view. Meanwhile, a certain part of students considers athletes as the "heroes of our time". At the same time, the majority of students noted that athletes are not so "heroes of our time", "because money decides everything in sports, and such "heroes" cannot be as role models, as it does not correspond to the true values of sport".

Therefore, we can say that in our country, the sport has very quickly replaced its social purpose with the mission of "money-goods-money".

Sociological research has determined that the politicization and commercialization of sports have highlighted both explicit and latent social contradictions in relation to sports among young people. Sport has lost its social purpose, becoming a subject of political ambitions and an object of commercial relations.

The study revealed some features of the attitude among young people to the sport through the prism of its social and institutional status.

\section{References}

[1] Concept of the Federal Target Program 'Development of physical culture and sports in Russia for 2016-2020'. URL: http://www.minsport.gov.ru/koncepciaFCP16-20.doc.

[2] B. Ciomaga, C. Kent, "Rethinking the consequences of commercializing sport”, Sport, Ethics and Philosophy, 2015, vol. 9, 1, pp. 18-31.

[3] Scott R. Jedlicka, (2018) "Sport governance as global governance: theoretical perspectives on sport in the international system", International Journal of Sport Policy and Politics, 10, 2, pp. 287-304.

[4] M. Green, "Changing policy priorities for sport in England: the emergence of elite sport development as a key policy concern", Leisure Studies, 2004, 23, 4, pp. 365-385.

[5] Grix J. Jonathan., F. Carmichael, "Why do governments invest in elite sport? A polemic", International Journal of Sport Policy and Politics, 2012, 4, 1, pp. 73-90.

[6] V.I. Zholdak, S.G. Seyranov, "Management: monograph". Moscow, Physical Education, 2006, 372 p.

[7] David Carr, "On the Moral Value of Physical Activity: Body and Soul in Plato's Account of Virtue", Sport, Ethics and Philosophy, 2010, 4, 1, pp. 3-15.

[8] Michael W. Austin "Sport for the Sake of the Soul", Sport, Ethics and Philosophy, 2018, 12, 1, pp. 20-29.

[9] A.V. Kylasov, "Ringed sport. The origins and meaning of modern Olympism”. - M.: AIRO XXI. 2018, 328.

[10] Robert J. Lake "Sport in History: An Introduction", The International Journal of the History of Sport, 2012, 29, 18, pp. 2599-2601.

[11] Victor D. Cha "A Theory of Sport and Politics", The International Journal of the History of Sport, 2009, 26, 11, 1581-1610.

[12] Henk Erik Meier, M. Mutz, "Political regimes and sport-related national pride: a cross-national analysis", International Journal of Sport Policy and Politics, 2009, 10, 3, pp. 525-548.

[13] G. Philip, "War without weapons". M.: Soviet sport. 2002, 398.

[14] F. Voigt, "Relations between Sport and Politics," Sport and Society: Materials of the World. scientific Congr. M.: Physical education and sport. 1981, pp. 46-50.

[15] W. Daume, "Sport as a continuation of politics," Sport and Society: Materials of the World. scientific Congr. M.: Physical education and sport. 1981, pp. 11-23. 
Pedagogico-pshychological and medico-biological problems of physical culture and sport. 2017, vol. 12(1), pp. 10-15. DOI: 10.14526/01_2017_177

[21] Alexsandr S. Kuznetsov. Russian Professor's meeting. Russian Journal of Physical Education and Sport. 2019, 14(1), pp. 17-22. DOI: 10.14526/2070-4798-2019-14-1-18-24

[22] G. Khachatryan, "About the Olympic "labor migrants". URL: http://centero.ru/opinions/obolimpijskikh-trudovykh-migrantakh.

[19] " $80 \%$ of sports betting in the world is done illegally". URL: http://www.stavki.info/index.php?id=917\&page=readnews

[20] Zinaida M. Kuznetsova, Jury D. Ovchinnikov, Lubov V. Horkova. The period of fatigue study in the training process of women-boxers. 